\title{
A transient model for explosive and phreatomagmatic eruptions
}

\author{
A.B. Starostin*, A.A. Barmin, O.E. Melnik \\ Institute of Mechanics, Moscow State University, 1-Michurinskii prosp., Moscow, 117192, Russia
}

Received 31 March 2004; accepted 1 September 2004

\begin{abstract}
We develop a model for explosive eruptions in cylindrical conduits generated by plug disruption at the top of the conduit. The eruption is calculated for a standard set of parameters for rhyolite. The model takes into account temperature variations and non-Newtonian magma rheology. We analyzed the influence of principal parameters such as fragmentation criteria, magma rheology, and initial conditions. We conclude that the variation of magma temperature is less than $70 \mathrm{~K}$ during eruption, and the model with bubble concentration-dependent viscosity leads to the increase of the steady discharge rate by about $40 \%$.

The eruption model is extended to include interaction between magma in the conduit and water in a surrounding aquifer. The phreatomagmatic eruption is also initiated by plug disruption. Two cases of initial aquifer pressure are considered: magmastatic and hydrostatic. These cases are valid for confined and unconfined aquifers. For the first case (confined aquifer), water influx influences the conduit flow soon after plug disruption and leads to the additional peaks of discharge rate; for the second case (unconfined aquifer), a purely magmatic, explosive eruption of longer duration is followed by a phreatomagmatic phase. In both cases, magma discharge rate increases by $10-100 \%$ in comparison with purely magmatic eruption.
\end{abstract}

(C) 2005 Elsevier B.V. All rights reserved.

Keywords: magma; explosive eruption; fragmentation front; aquifer; phreatomagmatic eruption

\section{Introduction}

The significant hazard posed by explosive volcanic eruptions has motivated widespread study of these

\footnotetext{
* Corresponding author. Tel.: +7 95939 5286; fax: +7 95939 0165 .

E-mail addresses: starab@yandex.ru (A.B. Starostin), barmin@imec.msu.ru (A.A. Barmin),melnik@imec.msu.ru (O.E. Melnik).
}

phenomena and many models of explosive eruptions have been published (Wilson et al., 1980; Slezin, 1984; Barmin and Melnik, 1993; Woods, 1995; Melnik, 2000; Papale, 2001; Slezin, 2003; and others). Most of these models are steady state and one-dimensional. Here we present a transient model of explosive eruption that considers the main physical processes. Magma flow in the conduit is modeled as a two-phase homogeneous fluid. We use this model to investigate eruption dynamics and magma-water interaction. 
During a phreatomagmatic eruption, intensive magma-water interaction can have a strong influence on the dynamics of the eruption, as happened on Santorini, 1640 BC (Pfeiffer, 2001), Vesuvius, 79 AD (Sheridan et al., 1981), and other volcanoes. There are several different mechanisms by which water may interact with the magma, for example, seawater, or water from a crater lake, can penetrate the upper part of volcanic conduit if the top of the edifice has been damaged; ground water can be injected from an aquifer as the conduit is being eroded. The depth and the scale of the magma-water contact zone may vary greatly and they are poorly constrained by observations. When water infiltrates the conduit, the water vaporizes and expands while the magma cools and fragments. Expansion of the mixture induces the phreatomagmatic explosions. For a small amount of water, influence of its injection is negligible, whereas a large amount of water prevents magma from explosions. Wohletz (2002) investigates the optimum magma/water mass ratio for maximum explosivity of phreatomagmatic event. However, the mass ratio itself depends on the dynamics of mingling of the two phases. How far and how fast water penetrates the magma depends on two factors, the vapor film on the contact surface of the phases oppose the mingling, whilst the different instabilities on the contact surface produce a finer mingling. The relationship between magma/water mass ratio, mingling processes, and explosivity have been investigated experimentally in several experimental studies (White, 1996; Wohletz, 2002; Zimanowski and Büttner, 2002). These studies confirm magma-water interaction as the most important process in phreatomagmatic events. In our phreatomagmatic eruption model, we mostly concentrate on magma flow in the conduit and water flow in the aquifer and we assume an equilibrium interaction between the flows.

\section{Explosive eruption modelling}

\subsection{Physical model and governing equations}

In this section we develop a model for a purely magmatic eruption. Explosive eruptions often start with the disruption of a lava dome or a cryptodome. Explosive activity is commonly triggered by lava- dome collapse, as observed at the Soufrière volcano, Montserrat (Robertson et al., 1998; Druitt et al., 2002), or by collapse of a volcanic edifice, as at Mount St. Helens (Voight et al., 1999). In both cases, disruption of the material in the upper part of volcanic conduit, referred to as the volcanic "plug," causes magma fragmentation and rapid acceleration of the fragmented material. Simultaneously, a rarefaction wave propagates down the conduit causing rapid bubble growth by decompression and volatile exsolution. This, in turn, leads to further fragmentation, sustaining the eruption.

We assume that bubbles are nucleated in a single event which occurs when magma pressure reaches the saturation value for dissolved volatiles. The bubbles are filled with volatiles exsolved from the melt (only $\mathrm{H}_{2} \mathrm{O}$ is considered in the model). The bubbly liquid has a density $\rho_{\mathrm{m}}$ of $1000-2500 \mathrm{~kg} \mathrm{~m}^{-3}$ and a viscosity $\mu$ of $10^{6}-10^{9} \mathrm{~Pa} \mathrm{~s}$ leading to a rather slow ascent velocity $v$ of $1-10 \mathrm{~m} \mathrm{~s}^{-1}$; hence, the Reynolds number $R e=\rho_{\mathrm{m}} v D / \mu$ in the bubbly liquid is smaller than 1 ( $D=30-50 \mathrm{~m}$ conduit diameter), and we can apply the Poiseuille's law for the wall friction. The high viscosity of the magmatic liquid and the small bubble radius ensure that bubble rise relative to the melt is negligible. We assume sufficiently rapid diffusion that dissolved water concentration $c$ is always equal to its equilibrium value according Henri's law. We use the formula for viscosity as function of concentration $c$ and temperature $T$ suggested in Hess and Dingwell (1996). We account for the influence of bubbles on the suspension viscosity using the method proposed in Llewellin and Manga (2005-this issue) and discuss the effect that this has on the dynamics of eruption.

We assume that the bubbly magma fragments immediately when the gas volume fraction reaches a critical value $\alpha_{\text {cr }}$ at which point it undergoes a transition to a gas-particle dispersion. Following Sparks (1978), we assume that fragmentation occurs at a front, with position $x_{\mathrm{f}}$, where the gas fraction is equal to $\alpha_{\mathrm{cr}}$.

After fragmentation, the wall friction is negligible in the comparison with the gravity force because it is controlled by the relatively low turbulent viscosity of the gas phase. We assume that fragmentation is complete and that all of the gas in the bubbles is released to form a continuous gas phase which carries 
ash particles in a gas-particle dispersion. We assume that the ash particles are small and, consequently, that they have the same velocity as gas phase (Melnik, 2000).

Based on the assumptions presented above, we consider magma ascent as a homogeneous two-phase flow (melt and gas) with both phases having the same velocity $v$, temperature $T$, and pressure $P$. Since we assume complete fragmentation, the exsolved gas phase can be characterized by a single variable $\alpha$ (gas volume fraction) in both zones. The flow of magma in a cylindrical conduit with diameter $D$ is described by the following system of equations: mass conservation Eq. (1), momentum Eq. (2), energy Eq. (3), and additional relationships (4)-(8):

$$
\begin{aligned}
& \frac{\partial \rho}{\partial t}+\frac{\partial \rho v}{\partial x}=0 \\
& \frac{\partial \rho v}{\partial t}+\frac{\partial\left(\rho v^{2}+P\right)}{\partial x}=-\rho g-f_{\mu} \\
& \frac{\partial E}{\partial t}+\frac{\partial((E+P) v)}{\partial x}=-\rho g v-f_{\mu} v \\
& c=k_{\mathrm{p}} \sqrt{P} \\
& E=c_{\mathrm{m}} \rho T+\frac{\rho v^{2}}{2} \\
& \rho=\alpha \frac{P}{R T}+(1-\alpha) \rho_{\mathrm{m}} \\
& P=P(\alpha, T) \\
& \alpha \leq \alpha_{\mathrm{cr}} \quad f_{\mu}=\frac{32 \mu(c, T) v}{D^{2}} \\
& \alpha>\alpha_{\mathrm{cr}} \quad f_{\mu}=0
\end{aligned}
$$

Here $\rho, P, T, v$ are the density, the pressure, the temperature and the velocity of the mixture, $\rho_{\mathrm{m}}$ is the density of the pure melt, $\alpha$ is the gas volume fraction, $c$ is the mass concentration of water dissolved in the melt and $R$ is the universal gas constant for water vapour. The total energy per unit volume of magma, $E$, depends only on the magma temperature and its heat capacity, because the mass of the gas phase is negligibly small in comparison with the mass of the melt. The momentum equation contains the resistance force $f_{\mu}$ and gravity forces, which also enter into the energy equation.

\subsection{Equation of state, boundary and initial conditions}

In this section, we discuss the equation of state (7) and boundary and initial conditions for the governing equations.

The melt component is conserved in each packet of magma:

$$
\frac{\partial(1-\alpha)(1-c) \rho_{\mathrm{m}}}{\partial t}+\frac{\partial(1-\alpha)(1-c) \rho_{\mathrm{m}} v}{\partial x}=0
$$

By combining and integrating conservation laws (1) and (9) we find the ratio of pure melt density to magma density to be constant and equal to $l-c_{0}$, where $c_{0}$ is the initial concentration of dissolved gases. We can write this ratio down as (see Appendix A):

$\frac{(1-\alpha)(1-c)}{\alpha \frac{P}{\rho_{\mathrm{m}} R T}+(1-\alpha)}=\left(1-c_{0}\right)$

Using (10) together with Henri's law (4) and the equation of state (6), the pressure can be written as a function of gas volume fraction and temperature:

$$
\begin{aligned}
P(\alpha, T)= & \left(\frac{\Pi_{m}(T)}{2} \frac{1-\alpha}{\alpha}\right. \\
& \left.\times\left[\sqrt{\frac{1}{\Pi_{\mathrm{s}}}+\frac{4}{\Pi_{\mathrm{m}}(T)} \frac{\alpha}{1-\alpha}}-\frac{1}{\sqrt{\Pi_{s}}}\right]\right)^{2}
\end{aligned}
$$

where $\Pi_{\mathrm{s}}=c_{0}^{2} / k_{\mathrm{p}}^{2}, \Pi_{\mathrm{m}}(T)=\rho_{m} R T c_{0} /\left(1-c_{0}\right)$.

Formula (11) allows the pressure at fragmentation $P_{\mathrm{f}}=P\left(\alpha_{\mathrm{cr}}, T\right)$ to be calculated. $P_{\mathrm{f}}$ is a monotonous decreasing function of $\alpha_{\mathrm{cr}}$; consequently, high values of $\alpha_{\mathrm{cr}}$ lead to low pressures at fragmentation; hence, magma viscosity reaches higher values, and consequently, magma discharge is lower.

Eqs. (1)-(8) form the basis of our explosiveeruption model. We now consider the response of this model to disruption of the volcanic plug. Initially, the pressure under the plug is magmastatic, and the temperature is constant; above the plug, pressure and temperature are atmospheric:

$$
\begin{array}{ll}
t=0 & \\
x \leq x_{\mathrm{p}} & P(x)=P_{\mathrm{mst}}(x), T=T_{\mathrm{ch}} \\
x>x_{\mathrm{p}} & P=P_{\mathrm{atm}}, T=T_{\mathrm{atm}}
\end{array}
$$


The initial magmastatic pressure profile below the plug $P_{\mathrm{mst}}(x)$ is calculated from Eq. (2) for $v=0$ and Eq. (11):

$$
\begin{aligned}
& \frac{\mathrm{d} P_{\mathrm{mst}}}{\mathrm{d} x}=-\left(\alpha \frac{P_{\mathrm{mst}}}{R T}+(1-\alpha) \rho_{\mathrm{m}}\right) g \\
& \alpha=\frac{\rho_{\mathrm{m}}\left(k_{\mathrm{p}} \sqrt{P_{\mathrm{mst}}}-c_{0}\right)}{\frac{P_{\mathrm{mst}}}{R T}\left(1-c_{0}\right)+\rho_{\mathrm{m}}\left(c_{0}-k_{\mathrm{p}} \sqrt{P_{\mathrm{mst}}}\right)}
\end{aligned}
$$

Eqs. (13) and (14) are solved with the boundary condition $P_{\mathrm{mst}}\left(0, T_{\mathrm{ch}}\right)=P_{\mathrm{ch}}$ for $0<x<x_{\mathrm{p}}$ where $P_{\mathrm{mst}}\left(x_{\mathrm{p}}, T_{\mathrm{ch}}\right)$ determines the pressure drop at the plug $\Delta P=P_{\mathrm{mst}}\left(x_{\mathrm{p}}, T_{\mathrm{ch}}\right)-P_{\mathrm{atm}}$. There is no gas-particle dispersion below the plug as $\alpha\left(x_{\mathrm{p}}\right)<\alpha_{\mathrm{cr}}$.

For most explosive eruptions, the erupted volume is much smaller than the chamber volume; hence, we assume that at the bottom of the conduit, the chamber pressure and temperature remain constant. At the top of the conduit, the pressure is equal to atmospheric $P_{\text {atm }}$ when the exit velocity is subsonic; otherwise, no conditions can be specified.

\subsection{Calculations}

The system of equations is solved by the LaxFriedrichs method (LxF method) which is described in Appendix A. We run the model using the three sets of input parameters: "Standard" refers to standard set of parameters specified in Sahagian (2005-this issue) in which case $P_{\mathrm{ch}}=200 \mathrm{MPa}$; "Case 1" uses the same standard parameters except for the magma chamber pressure $P_{\mathrm{ch}}=150 \mathrm{MPa}$, similarly for "Case 2," except $P_{\mathrm{ch}}=175 \mathrm{MPa}$. The evolution of the discharge rate and fragmentation front position with time for each case are shown in Figs. 1 and 2, respectively. Fig. 1 shows that immediately after the disruption of the plug, the discharge rate grows abruptly as a shock wave exits the conduit. Fig. 2 shows the corresponding descent of the fragmentation front resulting from propagation of

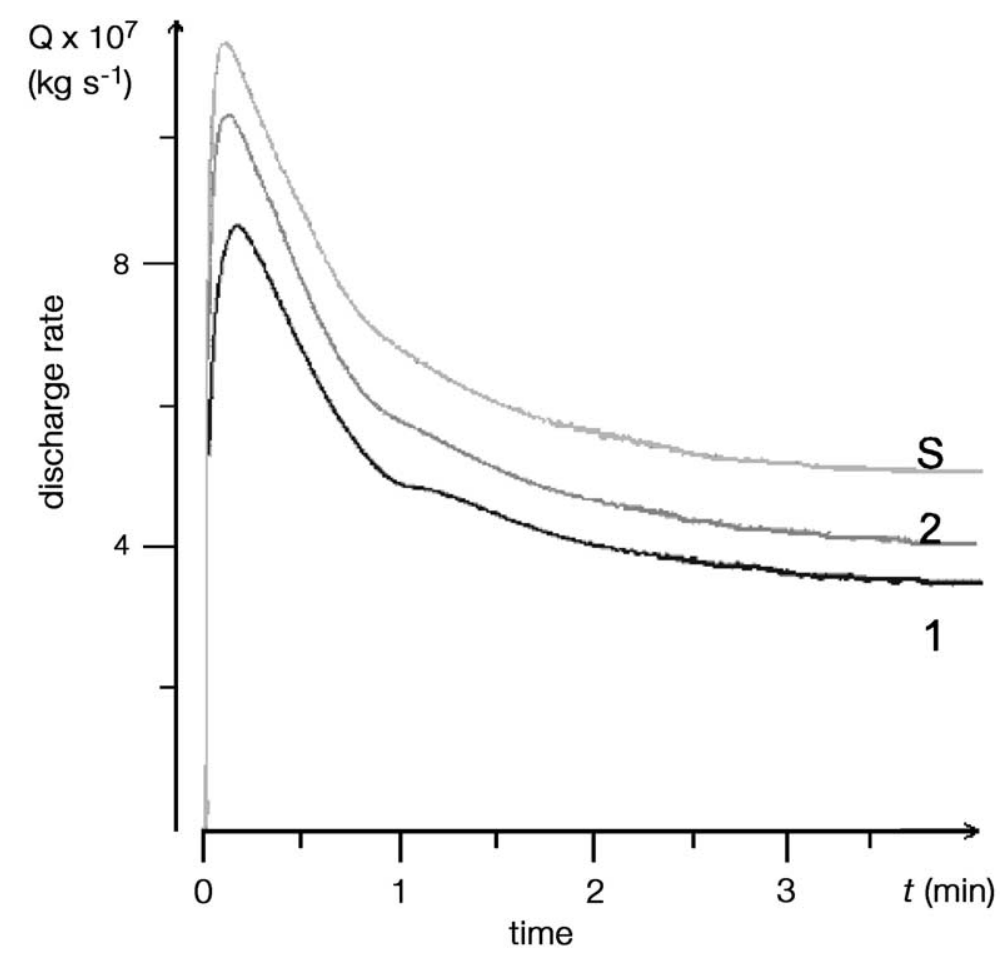

Fig. 1. Discharge vs. time for different pressure drops at the plug. Parameters of the calculations are detailed in Table 1. Curve 1 corresponds to "Case 1", curve 2 corresponds to "Case 2", and curve S corresponds to "Standard". 


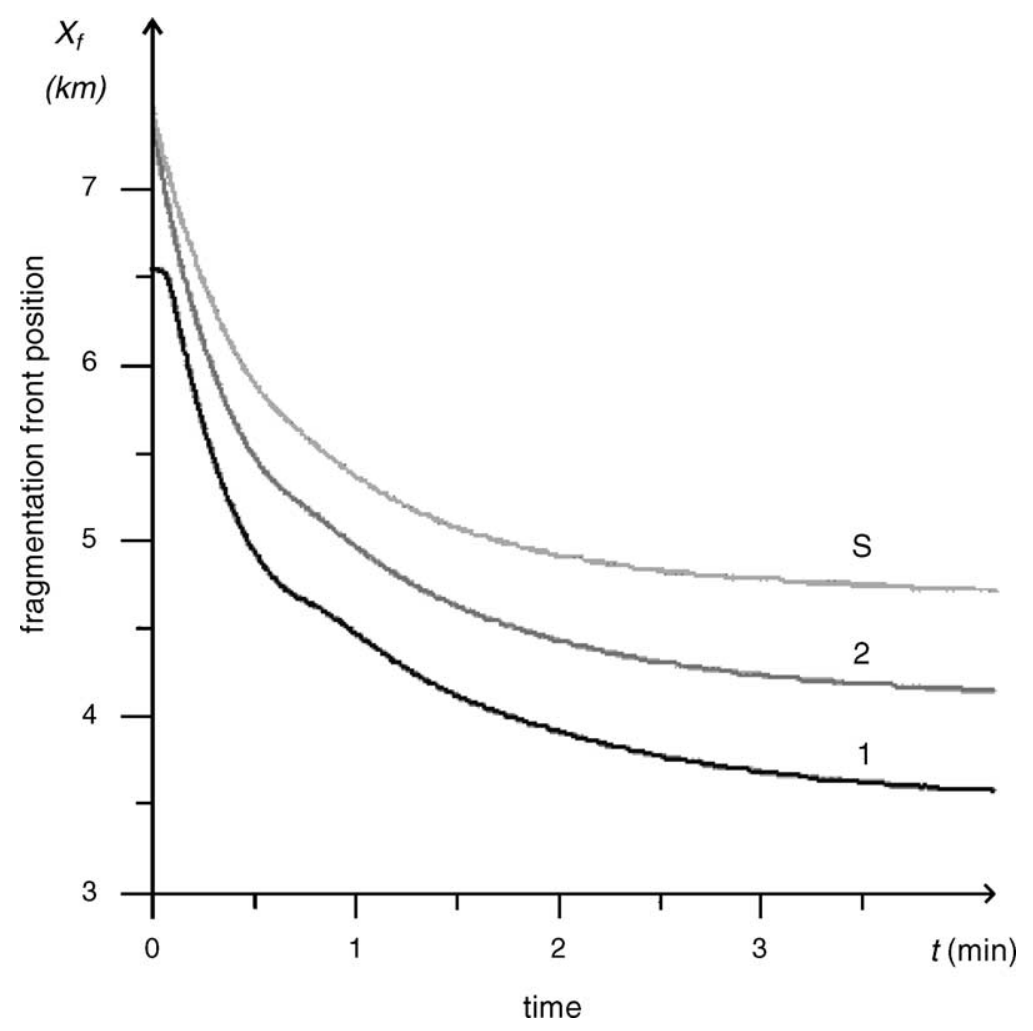

Fig. 2. Fragmentation front position vs. time for different pressure drops at the plug. Parameters of the calculations are detailed in Table 1. Curve 1 corresponds to "Case 1", curve 2 corresponds to "Case 2", and curve S corresponds to "Standard".

the rarefaction wave. After several minutes, the fragmentation wave stops at $x_{\mathrm{f}}=x_{\mathrm{f} 0}$ and the eruption stabilizes. The principal parameters for the stable eruption regime are presented in Table 1 for the three model runs-Case 1, Case 2, and Standard.

It can be seen from Table 1 that chamber pressure influences the pressure drop at the plug $\Delta P$, higher values of $\Delta P$ corresponding to higher chamber pressures. For stabilized eruption, a higher $P_{\text {ch }}$ also corresponds to a higher discharge rate $Q_{0}$ and a fragmentation position $x_{\mathrm{fo}}$ nearer the top of the conduit. A higher magma chamber pressure leads to a higher initial pressure drop which, in turn, leads to faster downward propagation of the fragmentation front. This results in a more intense transition from the bubbly magma into the gas-particle dispersion leading to a higher discharge peak at the initial stage of the eruption. Steady state is reached after approximately the same length of time in each of the three cases. For lower chamber pressure (Case 1), the degree of vesiculation of the magma at the base of the conduit is higher. This results in a lower position of the fragmentation level as the eruption stabilizes.

As eruption stabilizes, the total temperature variation of the flow is less than $70 \mathrm{~K}$. The magma loses most of its heat due to the expansion of the gas phase in the gas-particle dispersion zone. The temperature variation in this zone is about $50 \mathrm{~K}$.

\subsection{The role of bubble concentration-dependent viscosity}

So far, we have assumed the magma viscosity is a function of the concentration of the dissolved gas and temperature alone. Several works suggest that, in fact, the viscosity of the bubbly liquid depends on the steady and dynamic capillary numbers $\mathrm{Ca}, \mathrm{Cd}$ (Manga and Loewenberg, 2001; Llewellin et al., 2002a,b; Pal, 2003; Llewellin and Manga, 2005-this 
Table 1

Parameter set for three calculations of the explosive eruption

\begin{tabular}{|c|c|c|c|c|}
\hline & Parameters & Case 1 & Case 2 & Standard \\
\hline \multirow[t]{3}{*}{ Imposed } & chamber pressure & 150 & 175 & 200 \\
\hline & $\begin{array}{l}P_{\mathrm{ch}}(\mathrm{MPa}) \\
\text { steady discharge } \\
Q_{0}\left(\mathrm{~kg} \mathrm{~s}^{-1}\right)\end{array}$ & $3.31 \times 10^{7}$ & $4.02 \times 10^{7}$ & $5.1 \times 10^{7}$ \\
\hline & $\begin{array}{l}\text { fragmentation } \\
\text { vesicularity }\end{array}$ & 0.6 & 0.6 & 0.6 \\
\hline \multirow[t]{6}{*}{ Calculated } & $\begin{array}{l}\text { pressure drop at the } \\
\text { plug } \Delta P(\mathrm{MPa})\end{array}$ & 18.5 & 27.7 & 39.6 \\
\hline & $\begin{array}{l}\text { peak discharge } \\
\left(\mathrm{kg} \mathrm{s}^{-1}\right)\end{array}$ & $8.5 \times 10^{7}$ & $10.4 \times 10^{7}$ & $11.6 \times 10^{7}$ \\
\hline & exit velocity $\left(\mathrm{m} \mathrm{s}^{-1}\right)$ & 149 & 150 & 150 \\
\hline & $\begin{array}{l}\text { fragmentation } \\
\text { pressure } P_{\mathrm{f}}(\mathrm{MPa})\end{array}$ & 26 & 26 & 26 \\
\hline & exit pressure (MPa) & 2.65 & 3.21 & 4.05 \\
\hline & $\begin{array}{l}\text { fragmentation front } \\
\text { position } x_{\mathrm{fo}}(\mathrm{m})\end{array}$ & 3480 & 4130 & 4750 \\
\hline
\end{tabular}

issue). These dimensionless numbers depend on the undeformed bubble radius $a$, the bubble-liquid interfacial tension $\Gamma$, the melt viscosity $\mu$, the shear strain rate $\dot{\gamma}$ and its time derivative $\ddot{\gamma}$ (Llewellin et al., 2002a):

$$
C a=\frac{\mu a}{\Gamma} \dot{\gamma}, C d=\frac{\mu a}{\Gamma} \frac{\ddot{\gamma}}{\dot{\gamma}}
$$

If $C a<1$ and $C d<1$, the viscosity of the bubble suspension is higher than the melt viscosity, $\mu_{\mathrm{c}}=(1-\alpha)^{-1} \mu$; otherwise, $\mu_{\mathrm{c}}=(1-\alpha)^{5 / 3} \mu$, and the suspension viscosity is lower than the melt viscosity. These relationships are taken from Llewellin and Manga (2005-this issue) and represent the "minimum" effect of the bubbles on the viscosity of the suspension. To calculate $C a$ and $C d$, the average values for $\dot{\gamma}$ and $\ddot{\gamma}$ are used. If we assume a parabolic velocity profile, the average shear strain rate is

$$
\overline{\dot{\gamma}}=\frac{16}{3} \frac{v}{D}
$$

In our model, the radius of the bubble is not tracked; therefore, the bubble number density per unit volume of the bubble suspension $n$ is introduced and

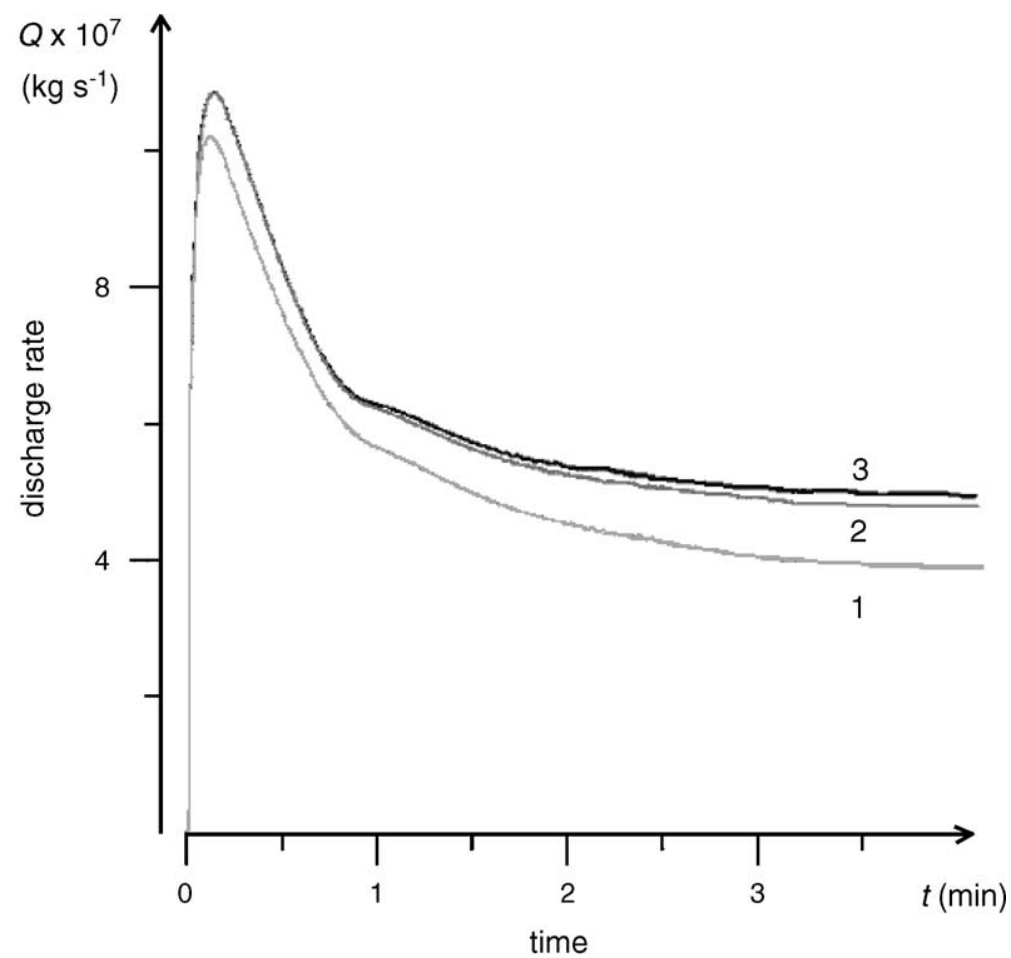

Fig. 3. Discharge vs. time for standard rhyolite parameters (1) and with Llewellin-Manga correction for $n_{0}=10^{15} \mathrm{~m}^{-3}(2) \mathrm{and}_{0}=10^{9} \mathrm{~m}^{-3}(3)$. 
the bubble radius can be calculated based on the definition of the gas volume fraction: $\alpha=4 \pi a^{3} n / 3$. As we assume no progressive bubble nucleation, the conservation law for the number density of the bubbles has the form:

$\frac{\partial n}{\partial t}+\frac{\partial n v}{\partial x}=0$

We combine Eq. (17) with the mass conservation law for the pure melt (9) and integrate to obtain (see Appendix A for details):

$\frac{n}{(1-c)(1-\alpha)}=\frac{n_{0}}{1-c_{0}}$

where $n_{0}$ is the number density of bubbles at saturation pressure $P_{\text {sat }}=\left(c_{0} / k_{\mathrm{p}}\right)^{2}$ immediately following nucleation, when bubble volume is negligibly small $(\alpha \approx 0)$. We use Eq. (18) to calculate the bubble radius:

$a=\left(\frac{3}{4 \pi} \frac{\alpha}{n}\right)^{\frac{1}{3}}=\left(\frac{3}{4 \pi} \frac{\alpha\left(1-c_{0}\right)}{(1-\alpha)(1-c) n_{0}}\right)^{\frac{1}{3}}$

We performed two model runs in which we included the effect of bubbles on the rheology of the suspension. We used standard rhyolite parameters and chose $n_{0}=10^{9} \mathrm{~m}^{-3}$ for one run and $n_{0}=10^{15} \mathrm{~m}^{-3}$ for the other in order to investigate the effect of natural variability in the bubble nucleation density. Eruption rates predicted by these model runs are shown in Fig. 3, along with the results for a model run using the standard rhyolite parameters and neglecting the effects of bubbles on the suspension's rheology. Fig. 3 shows that the magma discharge rate in the steady-state regime increases by almost $40 \%$ when the effect of bubbles on suspension rheology is considered. The calculated discharge only slightly depends on the particular choice of $n_{0}$ in the wide range of this parameter.

\section{Phreatomagmatic eruption modelling}

We now consider phreatomagmatic eruptions induced by the influx of phreatic water from an aquifer into the conduit.

The injection of water into the conduit results in low-temperature deposits, dramatic changes of dis- charge rate, and other unsteadiness of eruption processes. Analysis of deposits at the Furnas volcano, São Miguel, Azores (Cole et al., 1995), and at the Kos Plateau Tuff, Greece (Allen and Cas, 1998), indicate that transitions between "wet" and "dry" regimes are associated with fluctuations in discharge rate. Many phreatomagmatic eruptions follow a long phase of purely magmatic activity which can last for several hours (Vesuvius, 79 AD, Arrighi et al., 2001) or days (Tolbachik, 1975; Doubik and Hill, 1999). In such cases, the transition to the phreatomagmatic phase can significantly increase the discharge rate (Sheridan et al., 1981; Doubik and Hill, 1999; White and Schmincke, 1999).

\subsection{Model development}

Fig. 4 illustrates the volcanic system, including the aquifer, before the eruption when the conduit is

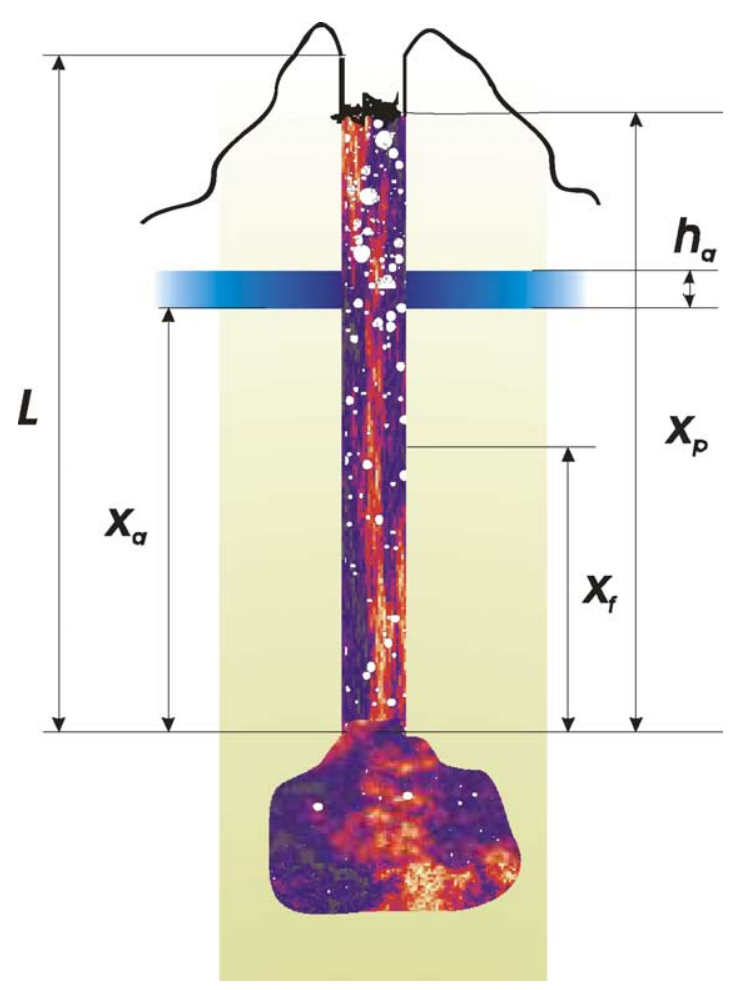

Fig. 4. Schematic view of the volcanic system containing the aquifer before plug disruption. The conduit is plugged and aquifer edges are not permeable for water to inject into the conduit. 
still plugged. The geometry of the system is axisymmetric; the aquifer surrounds the conduit and has no horizontal limits. The aquifer contacts the conduit at the position $x_{\mathrm{a}}$ and has thickness $h_{\mathrm{a}}$. The magmawater interaction induces complicated physical processes (White, 1996; Wohletz, 2002), which we treat as averaged in time and space. We make the following assumptions about the influence of the influx:

(1) The thickness of the aquifer is much smaller than the length of the conduit $h_{\mathrm{a}} \ll L$. The influx zone is the cylinder formed by the aquifer-conduit interface. We assume that this interface is small compared with the flow domains either of magma or of water; therefore, we do not consider the distribution of the parameters in the cross section of the influx zone but assume that the pressure at the edge of the aquifer $P_{\mathrm{w}}(0.5 D)$ is equal to the pressure within the influx zone $P_{\mathrm{a}}$, where $P_{\mathrm{a}}$ is the conduit pressure averaged along the influx zone:

$P_{\mathrm{a}}=\frac{1}{h_{\mathrm{a}}} \int_{x_{\mathrm{a}}}^{x_{\mathrm{a}}+h_{\mathrm{a}}} P(x) \mathrm{d} x$

(2) The characteristic time of water injection from the aquifer to the conduit is significantly longer than the characteristic time of its vaporization (Barmin et al., 2003). Therefore, incoming water is immediately heated up to the equilibrium boiling temperature $T_{\mathrm{e}}$ and vaporizes. The resulting vapour immediately reaches the mixture temperature.

(3) The resulting vapour either mixes with the free gas phase if the aquifer intercepts the conduit in the gas-particle dispersion regime or forms new bubbles if the aquifer intercepts the conduit in the bubbly liquid regime. This is perhaps the most voluntary assumption, but we make it since there are no direct observations of magma-water mingling in the conduit during the phreatomagmatic episodes.

As a consequence of these assumptions, water mass flux $j$ and associated heat flux $q$ must be added to the governing equations. The heat flux $q$ is the quantity of heat necessary, per unit time, to vaporize the injected mass of water $j$ and to heat it to the mixture temperature. Eqs. (1) and (3) are modified as follows:

$$
\begin{aligned}
& \frac{\partial \rho}{\partial t}+\frac{\partial \rho v}{\partial x}=j \\
& \frac{\partial E}{\partial t}+\frac{\partial((E+P) v)}{\partial x}=-\rho g v-f_{\mu} v-q
\end{aligned}
$$

The flow of water within the aquifer is described with the mass conservation law (22), Darcy's law (23), and the equation of state for water (24):

$$
\begin{aligned}
& m \frac{\partial \rho_{\mathrm{w}}}{\partial t}+\operatorname{div} \rho_{\mathrm{w}} u=0 \\
& u=-\frac{k}{\mu_{\mathrm{w}}} \operatorname{grad} P_{\mathrm{w}} \\
& \rho_{\mathrm{w}}=\rho_{\mathrm{w} 0}\left(1+\alpha_{\mathrm{w}}\left(P_{\mathrm{w}}-P_{\mathrm{atm}}\right)\right)
\end{aligned}
$$

Here, $\rho_{\mathrm{w}}, P_{\mathrm{w}}$, and $u$ are the density, the pressure, and the velocity of the water, respectively, $\mu_{\mathrm{w}}$ is the water viscosity, $\alpha_{\mathrm{w}}$ is the water compressibility coefficient, $m, k$ are, respectively, the porosity and the permeability of the aquifer. Water temperature in the aquifer $T_{\mathrm{w}}$ is assumed to be constant.

As the aquifer has no horizontal limits and its thickness is much smaller than conduit length, the flow in the aquifer is assumed to be planar and axisymmetric. The polar coordinate system is the most appropriate for solving Eqs. (22)-(24) in this case. The parameters in the aquifer are functions of the distance to the conduit $r$ and the time $t$.

We calculate the rates of phreatic water mass and heat influxes into the conduit using Darcy's law (23):

$$
\begin{aligned}
& x_{\mathrm{a}} \leq x \leq x_{\mathrm{a}}+h_{\mathrm{a}} \\
& j=\left.\frac{4 \rho_{\mathrm{w}} k}{D m} \frac{\partial P_{\mathrm{w}}}{\partial r}\right|_{r=D / 2} \\
& q=j\left(c_{\mathrm{w}}\left(T_{\mathrm{e}}-T_{\mathrm{w}}\right)+c_{\mathrm{v}}\left(T-T_{\mathrm{e}}\right)+\lambda_{\mathrm{w}}\right) \\
& 0 \leq x<x_{\mathrm{a}}, \quad x_{\mathrm{a}}+h_{\mathrm{a}}<x \leq L \\
& j=0 \quad q=0
\end{aligned}
$$

where $c_{\mathrm{W}}$ and $c_{\mathrm{v}}$ are the heat capacities of water and vapor, $\lambda_{\mathrm{w}}$ is the latent heat of vaporization. The 
equilibrium boiling temperature $T_{\mathrm{e}}$ is a function of the pressure in the influx zone and is taken from Barmin et al. (2003).

The total water influx from the aquifer per time unit $J$ is the product of the volume of the influx zone and the water mass flux:

$J=\frac{\pi}{4} D^{2} h_{\mathrm{a}} j$

The magma discharge in the conduit increases above the influx zone due to this input. In all our calculations, $J$ is smaller than $20 \%$ of the average magma discharge.

We use the transient model (2),(4)-(9),(21)-(25) to consider the development of a phreatomagmatic eruption after plug disruption. The boundary and initial conditions in the conduit are the same as were discussed above in Section 2.2. The chamber temperature is $1300 \mathrm{~K}$. This allows us to consider the strongest influence of the water influx. The aquifer position $x_{\mathrm{a}}$ is deeper than the plug position $x_{\mathrm{p}}$ (Fig. 4).

We consider two cases with different initial pressures in the aquifer. The first case considers magmastatic initial pressure in the aquifer; it models the situation when the aquifer is confined (not freely connected to the surface). The second case assumes the hydrostatic pressure, corresponding to the unconfined aquifer connected to the surface. Other aquifer parameters are taken from Delaney (1982) and Troise et al. (2001). Aquifer porosity $m$ is 0.2 , its permeability $k$ is $10^{-11} \mathrm{~m}^{-2}$ (confined aquifer) or $5 \times 10^{-12} \mathrm{~m}^{-2}$ (unconfined aquifer). The temperature of water in the aquifer is $290 \mathrm{~K}$. The thickness of the aquifer is taken to be $h_{\mathrm{a}}=100 \mathrm{~m}$ : this defines the length of the influx zone.

\subsection{Regimes of water injection and their steady-state features}

Before considering the transient results let us discuss the results of the steady-state model deduced from the Eqs. (2),(4)-(9),(21) with constant mass and heat influxes. By means of the steady-state model, an explosive eruption with constant water injection was studied in Barmin et al. (2003). Barmin et al. recognize three regimes of water injection corresponding to the fragmentation front position relative to the aquifer. If $x_{\mathrm{a}}<x_{\mathrm{f}}$, the influx occurs in the bubbly liquid zone we name this situation Regime 1 . If the fragmentation front is located in the influx zone: $x_{\mathrm{a}}+h_{\mathrm{a}} \geq x_{\mathrm{f}} \geq x_{\mathrm{a}}$, we name this situation Regime 2. If $x_{\mathrm{a}}+h_{\mathrm{a}}>x_{\mathrm{f}}$ influx occurs in the gas-particle dispersion zone, we name this situation Regime 3. The regimes are presented in Fig. 5 for a constant depth aquifer and

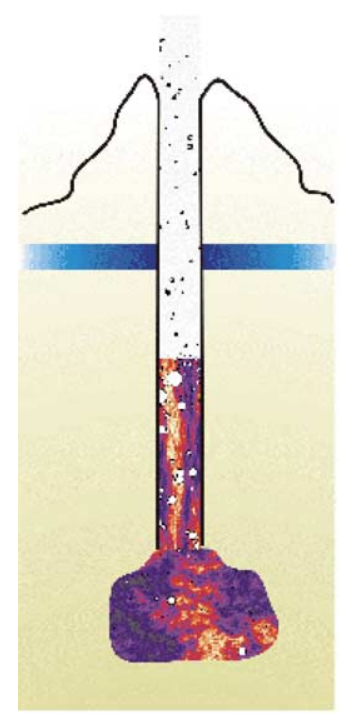

Regime 1

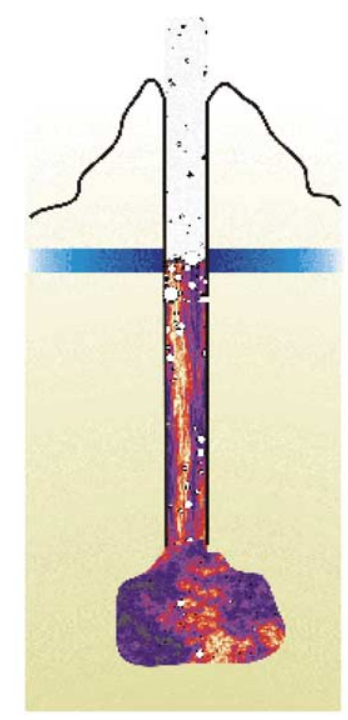

Regime 2

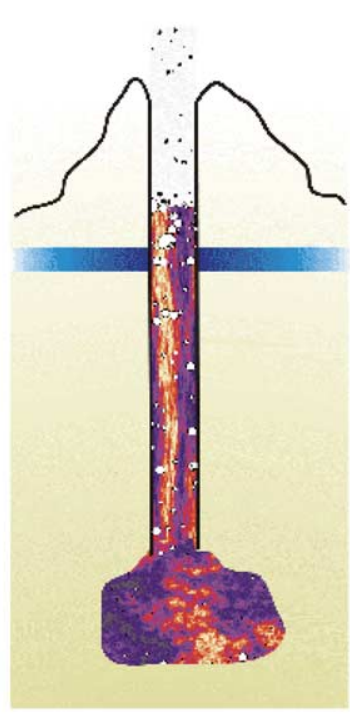

Regime 3

Fig. 5. Schematic view of the volcanic system in the different regimes. 
different fragmentation front positions. If an eruption is steady state, it occupies one of the regimes. A transient eruption triggered by a plug disruption starts in Regime 1 and may undergo a transition to each of the regimes before stabilization in the one of them. If the system stays in a certain regime for a long time, the transient behaviour acquires the steady-state features of the regime, which are considered below.

Fig. 6 shows the dependence of steady discharge rate $Q\left(x_{\mathrm{a}}, J\right)$ and steady fragmentation front position $x_{\mathrm{f}}\left(x_{\mathrm{a}}, J\right)$ on $x_{\mathrm{a}}$ as it changes from $0.02 L$ to $0.98 L$ $(L=5 \mathrm{~km})$ for different, fixed values of $J$. The dependency $Q\left(x_{\mathrm{a}}, J\right)$ is normalized on the discharge rate $Q_{0}=Q\left(x_{\mathrm{a}}, 0\right)$ for zero influx $J=0$. The dependency $x_{\mathrm{f}}\left(x_{\mathrm{a}}, J\right)$ is normalized on the fragmentation front position $x_{\mathrm{f} 0}=x_{\mathrm{f}}\left(x_{\mathrm{a}}, 0\right)$ for zero influx $J=0$. Three regimes are clearly seen by changes in the slopes of the curves.

For Regime 1, when water infiltrates beneath the fragmentation front, the water injection significantly changes the properties of the column of the bubbly liquid above the influx zone (see Fig. 5). The gas volume fraction $\alpha$ of the column increases due to the additional free gas fraction and the temperature of the column decreases due to vaporization of the injected water. The temperature of the mixture decreases by about $100 \mathrm{~K}$; consequently, the melt viscosity increases by a factor of 4 according to Hess and Dingwell (1996). With the increase in $\alpha$ and decrease in $T$, the fragmentation happens earlier than in the case without influx $(J=0)$. Thus, the water injection shortens the bubbly liquid zone. Fragmentation depth increases monotonically with the increase in $J$. For Regime 1, fragmentation front position is deeper than $x_{\mathrm{fo}}$ and discharge rate is higher than $Q_{0}\left(Q \sim 1\right.$ to $\left.1.8 Q_{0}\right)$.

For Regime 3 , the influence of the infiltrating water is the weakest and it does not lead to a large variation in the fragmentation front position and discharge rate ( $Q \sim 0.7$ to $\left.1.3 Q_{0}\right)$. Injected water turns to vapour, expands and flows out with gas-particle dispersion; it does not influence the fragmentation process directly as it does in Regime 1 . The injected water may adjust to the discharge rate and the exit discharge $Q\left(x_{\mathrm{a}}, J\right)+J$ may be higher than $Q_{0}$. But due to the choked conditions at the conduit, the exit discharge may be lower than $Q_{0}$.
For Regime 2, the fragmentation occurs in the influx zone. The injected water is enough to bring the system to fragmentation directly in the influx zone. A large water influx may induce fragmentation much deeper than $x_{\mathrm{fo}}$. Thus, the bigger the influx, the wider the interval of $x_{\mathrm{a}}$ values for Regime 2 .

For the steady eruptions considered, the total water influx $J$ does not exceed $20 \%$ of the steady magma discharge $Q_{0}$; nevertheless, in each regime, the temperature of the mixture decreases by about $100 \mathrm{~K}$ as the flow passes the influx zone.

\subsection{Transient results: confined aquifer}

Let us assume that a confined aquifer has magmastatic pressure before the eruption starts. The aquifer permeability $k$ is equal to $5 \times 10^{-12} \mathrm{~m}^{2}$ and the aquifer porosity $m$ is equal to 0.2 . To get the initial value of pressure, we average the magmastatic pressure along the influx zone according to Eq. (26):

$P_{\mathrm{a}}=\frac{1}{h_{\mathrm{a}}} \int_{x_{\mathrm{a}}}^{x_{\mathrm{a}}+h_{\mathrm{a}}} P_{\mathrm{mst}}(x) \mathrm{d} x \approx P_{\mathrm{mst}}\left(x_{\mathrm{a}}+0.5 h_{\mathrm{a}}\right)$

Figs. 7 and 8 demonstrate the discharge rate, the fragmentation front, the total water influx, and the magma temperature at the influx zone vs. time for the two cases of aquifer positions (respectively, $x_{\mathrm{a}}=2.15 \mathrm{~km}$ and $1.9 \mathrm{~km}, L=5 \mathrm{~km}$ ). Both cases are similar at the initial stage. After plug disruption at $x_{\mathrm{p}}=5 \mathrm{~km}$, the discharge rate reaches its maximum after a few seconds. The influx appears as the rarefaction wave propagates down and reaches the aquifer. The water injection accelerates the fragmentation front. The front moves down, more rapidly increasing the amount of fragmented material and leads to the second maximum of discharge at about 1 min after plug disruption. For both aquifer positions, the second discharge peak due to the water injection exceeds the first one caused by plug disruption. Over about $1 \mathrm{~min}$ the water influx reaches its maximum value. The fragmentation front stops in the influx zone (Regime 2 ), and while it is keeping a constant position about $x=2.1 \mathrm{~km}$, the water influx fades as a rarefaction wave propagates inside the aquifer and pressure gradient decreases. When water influx becomes low the front starts to ascend and the discharge rate decreases. Due to the influx of the water from outer parts of the 

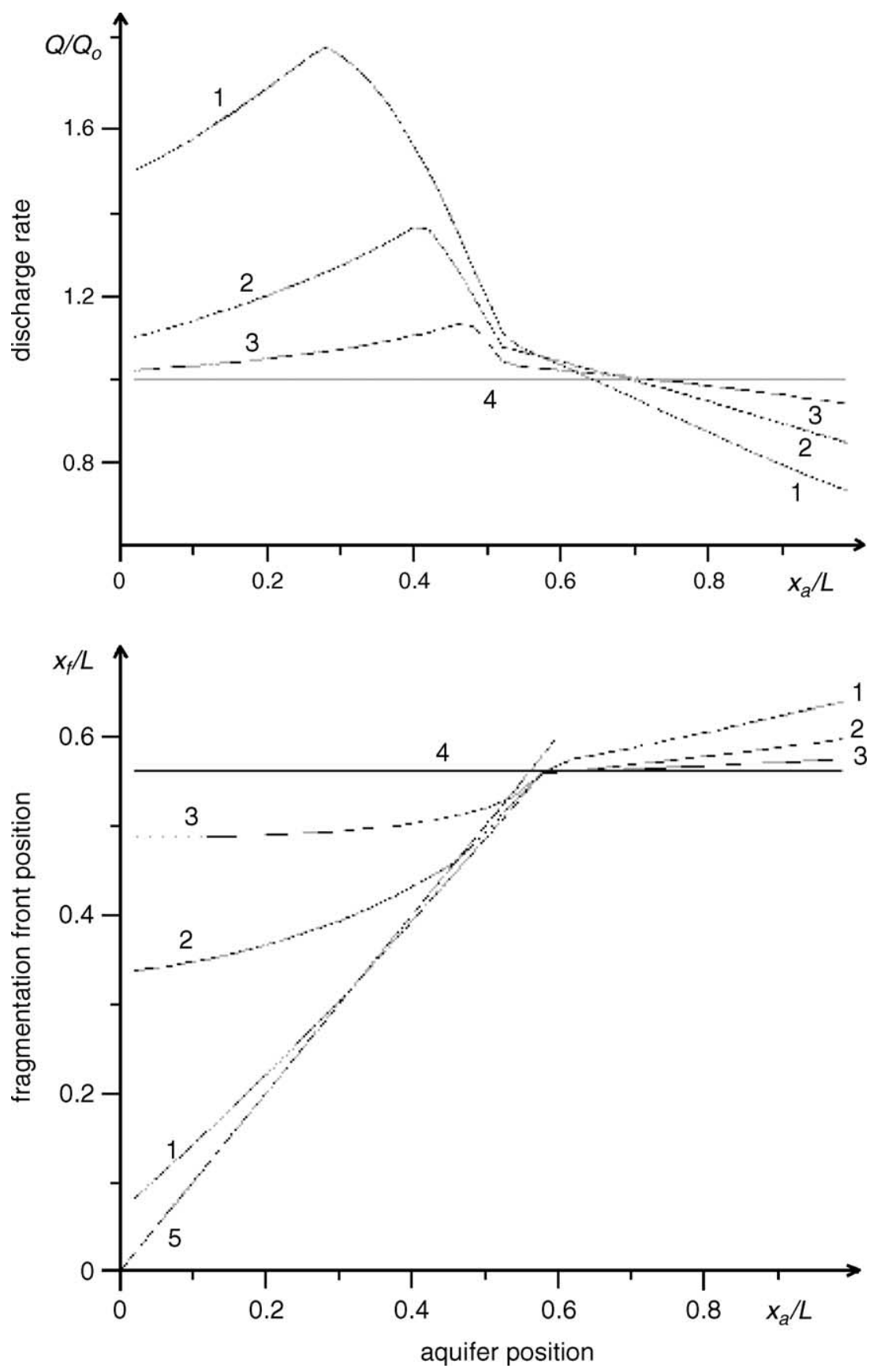

Fig. 6. Steady phreatomagmatic eruption: Steady discharge and fragmentation front position vs. aquifer position for different influxes $J=18 \times 10^{5}, 6 \times 10^{5}, 2 \times 10^{5}, 0 \mathrm{~kg} \mathrm{~s}^{-1}$. At one-to-one line fragmentation front position and aquifer top coordinate are equal.

aquifer, the total water injection into the conduit increases again leading to fragmentation front descent and an increase in discharge.
For the case of a shallower aquifer (Fig. 7), the total water influx reaches a smaller maximum in each pulse and stabilizes in $5 \mathrm{~min}$. As a result, the discharge 

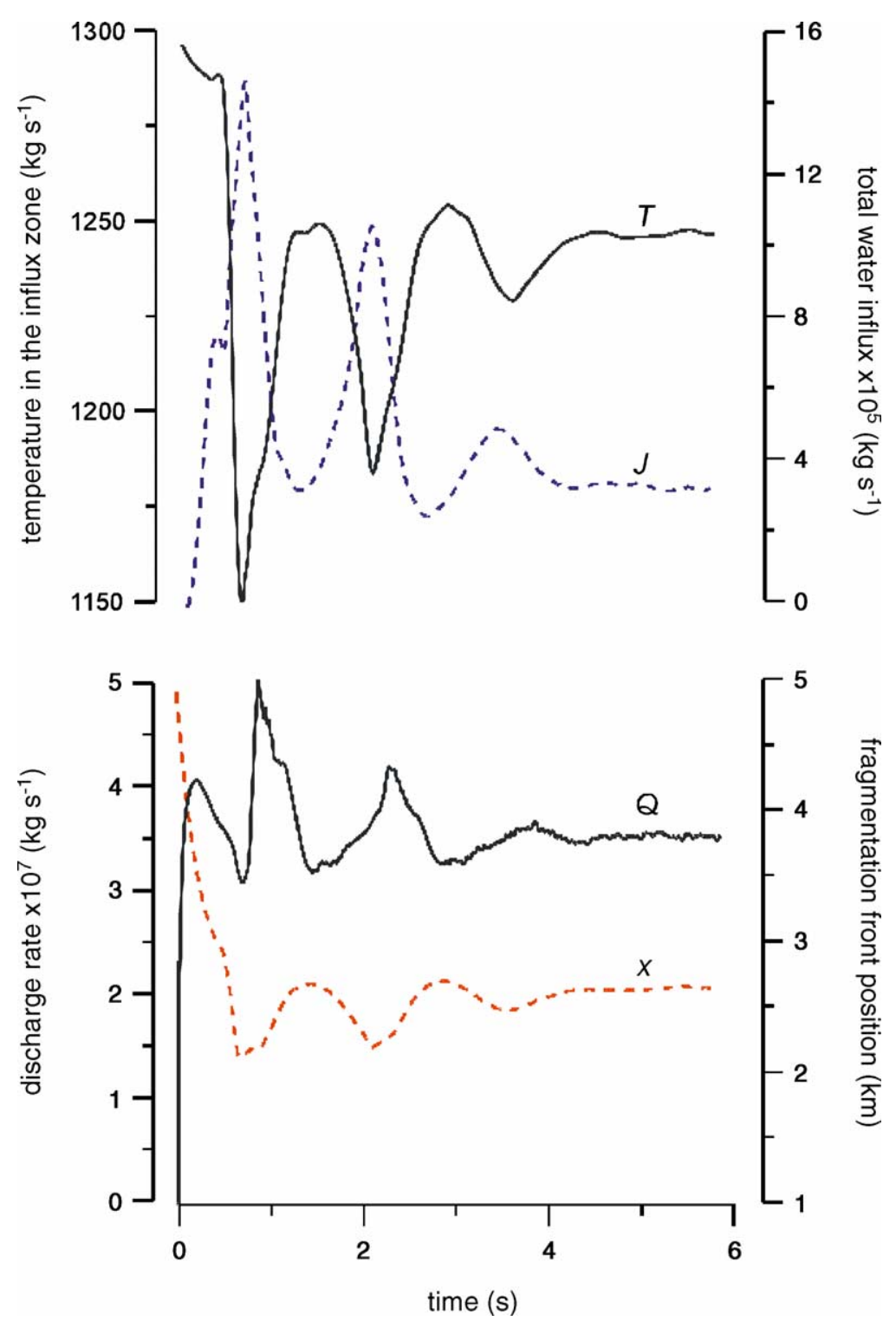

Fig. 7. Phreatomagmatic eruption with several peaks of discharge: Discharge $(Q)$, fragmentation front position $(x)$, total water influx $(J)$, and temperature in the influx zone $(T)$ vs. time for aquifer position $x_{\mathrm{a}}=1900 \mathrm{~m}$.

has several peaks of diminishing magnitude before it stabilizes.

For the case of a deeper aquifer (Fig. 8), the influx peaks repeat with an almost constant amplitude (curve $J$ ), causing the fluctuations of the magma discharge (curve $Q$ ). Their period is about $1-2 \mathrm{~min}$. The discharge fluctuations last for $40 \mathrm{~min}$. Their amplitude is about $10 \%$ of the average discharge, although the total water input $J$ is less than $10 \%$ of the average magma discharge $Q$. But nevertheless, the process stabilizes, because the water influx has a tendency to decrease as the part of the aquifer affected by the flow spreads out and the pressure gradient smoothes. During the oscillations, the system switches between Regimes 1 and 2. The oscillations cannot appear in Regime 3 because in that case, the influx influences 

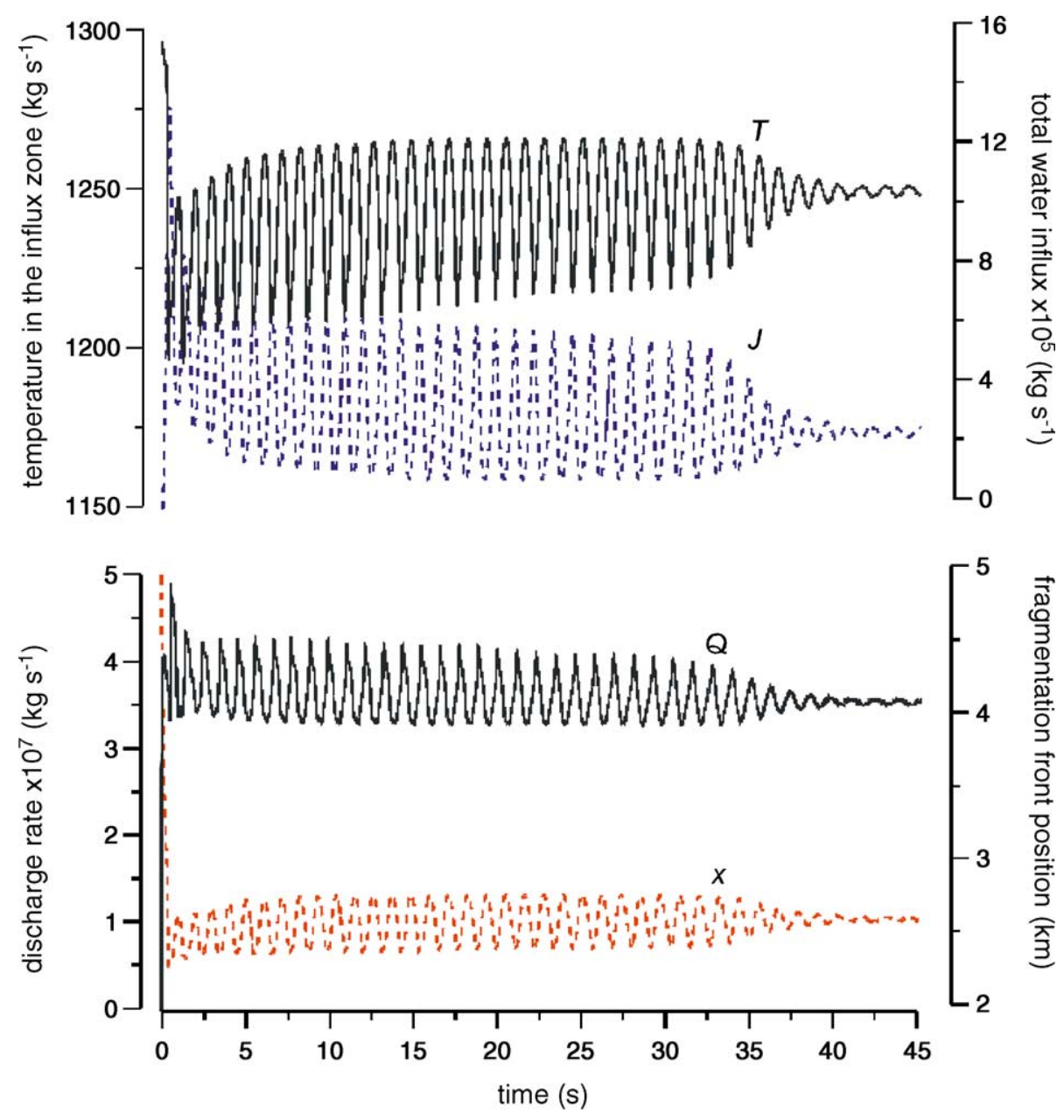

Fig. 8. Phreatomagmatic eruption with fluctuating discharge: Discharge $(Q)$, fragmentation front position $(x)$, total water influx $(J)$, and temperature in the influx zone $(T)$ vs. time for aquifer position $x_{\mathrm{a}}=2150 \mathrm{~m}$.

the fragmentation front position indirectly, by changes in the gas-particle dispersion zone.

The water influx evolution depends on the pressure distribution in the aquifer as follows from (25). Fig. 9 shows the pressure profiles in the aquifer. We can conventionally separate the aquifer into two ring zones surrounding the conduit. In Zone 1, closer to the conduit, the pressure profile changes according to the pressure evolution in the conduit. In Zone 2, the pressure always decreases with time because the average pressure at the aquifer-conduit interface is lower than the initial aquifer pressure; furthermore, the pressure profile becomes less steep and the influx has a tendency to decrease.
Fig. 10 compares the discharge evolution for purely magmatic eruptions and two phreatomagmatic eruptions with different aquifer position as discussed above $\left(x_{\mathrm{a}}=2.15 \mathrm{~km}\right.$ and $\left.1.9 \mathrm{~km}\right)$. After the plug disruption, in each case, the eruption initially evolves as if purely magmatic until the influx initiation. When there is no aquifer, the eruption stabilizes after approximately $1 \mathrm{~min}$ (Fig. 10, curve 1). When an aquifer is included in the model, the infiltration of water induces instability in the eruption which causes the fluctuation in the discharge rate visible in curves 2 and 3 of Fig. 10. The nature of these fluctuations varies from several discharge peaks (Fig. 10, curve 2) to long fluctuations of discharge (Fig. 10, curve 3). 


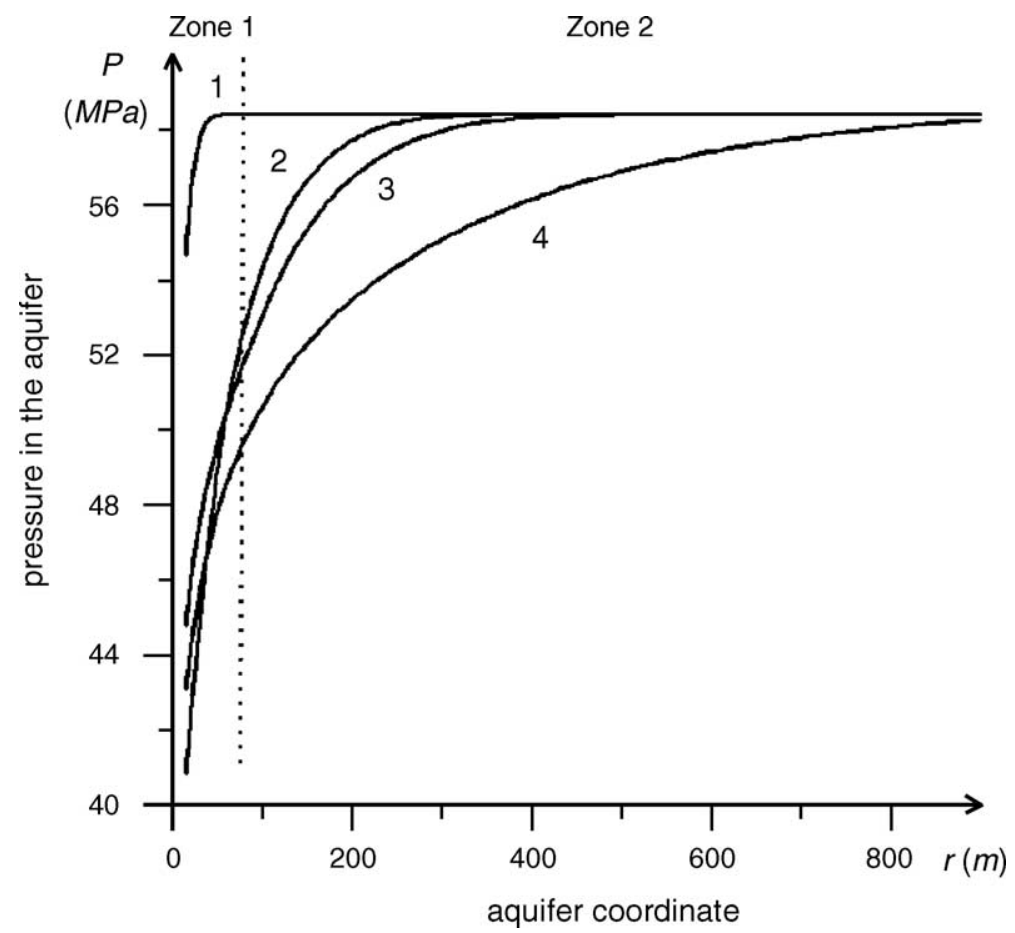

Fig. 9. Pressure profiles in the aquifer at the time $14 \mathrm{~s}$ (curve 1), $164 \mathrm{~s}$ (curve 2), $314 \mathrm{~s}$ (curve 3), and $2700 \mathrm{~s}$ (curve 4).

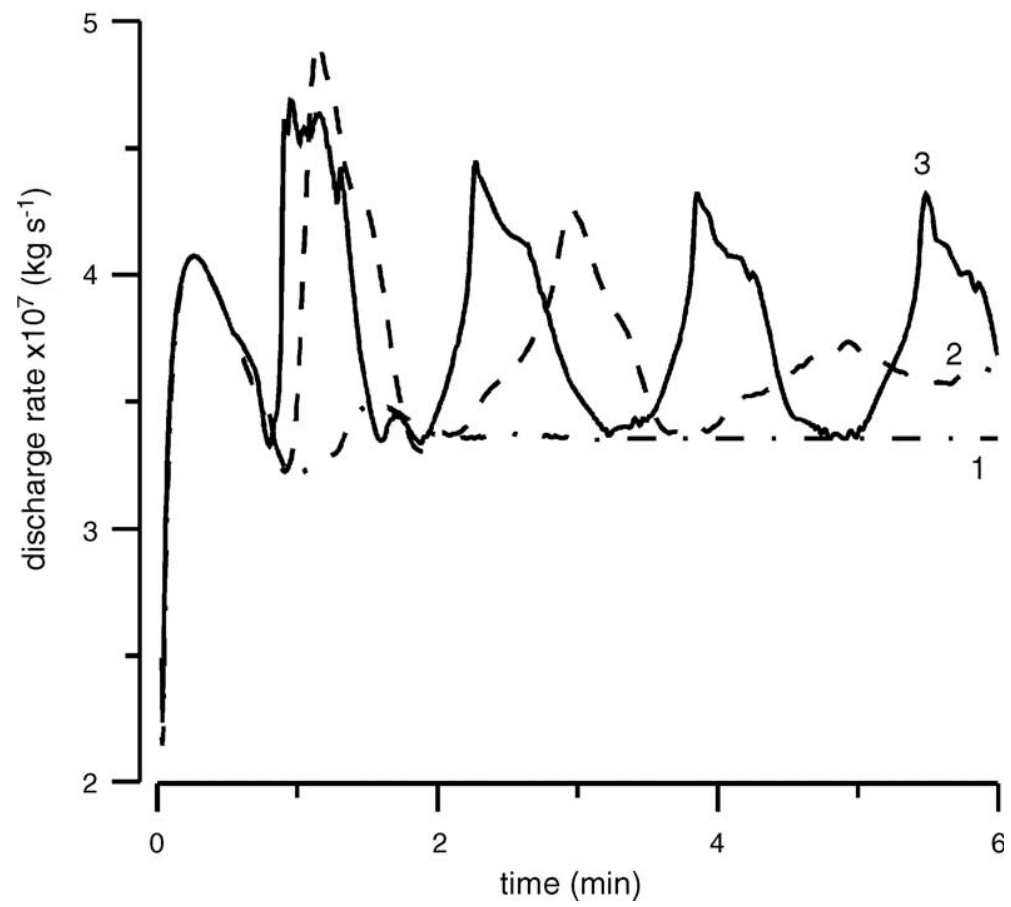

Fig. 10. Discharge vs. time for different aquifer positions. Curve 1 corresponds to the eruption without influx, curve 2 corresponds to the eruption with the aquifer at $x_{\mathrm{a}}=2150 \mathrm{~m}$, curve 3 corresponds to the eruption with the aquifer at $x_{\mathrm{a}}=1900 \mathrm{~m}$. 


\subsection{Transient results: unconfined aquifer}

Next, we consider the case of hydrostatic pressure in the aquifer (i.e., the aquifer is unconfined and has a free connection with the surface). We assume that aquifer permeability $k$ is equal to $10^{-11} \mathrm{~m}^{2}$ and the aquifer porosity $m$ is equal to 0.2 . To get the initial value of pressure, we average the hydrostatic pressure along the influx zone according to the Eq. (26):

$P_{\mathrm{a}}=\left(L-x_{\mathrm{a}}-0.5 h_{\mathrm{a}}\right) \rho_{\mathrm{w}} g+P_{\mathrm{atm}}$

In this case, the aquifer pressure remains lower than the conduit pressure and no influx occurs if the chamber pressure is fixed. During long-term Plinian
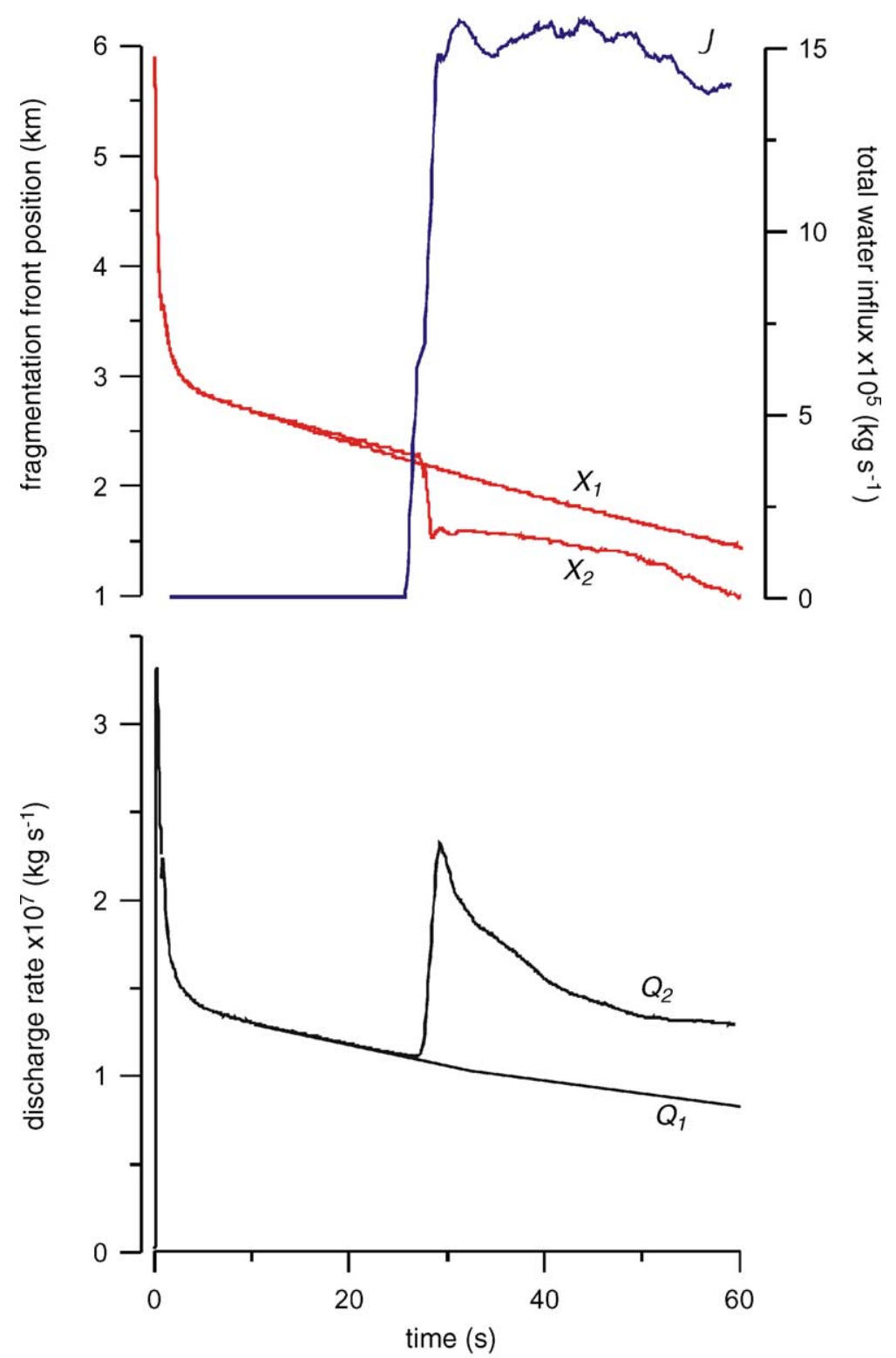

Fig. 11. Phreatomagmatic phase after long purely magmatic explosive eruption: Fragmentation front position $\left(x_{1}\right)$ and discharge $\left(Q_{1}\right)$ vs. time during eruption without aquifer influence. Fragmentation front position $\left(x_{2}\right)$, total water influx $(J)$, and discharge $\left(Q_{2}\right)$ vs. time during eruption with aquifer influence. 
eruptions, the chamber pressure decreases due to the evacuation of the magma from the chamber. We assume that the pressure change corresponds to the erupted volume (Woods and Koyaguchi, 1994):

$\frac{\mathrm{d} P_{\mathrm{ch}}}{\mathrm{d} t}=-\vartheta Q(0, t)$

Here, the coefficient $\theta$ depends on the chamber and wallrock properties (Woods and Koyaguchi, 1994). In our calculations, $\theta=10^{-3} \mathrm{~m} \mathrm{~s}^{-2}$.

Fig. 11 compares a purely magmatic explosive eruption with an explosive eruption which includes a phreatomagmatic phase. In the phreatomagmatic case, we assume that there is an aquifer at $x_{\mathrm{a}}=1.5 \mathrm{~km}$ $(L=7 \mathrm{~km})$. Fig. 11a shows the evolution of the fragmentation front for a purely magmatic eruption (curve $x_{1}$ ) and for an eruption with a phreatomagmatic phase (curve $x_{2}$ ). The figure also shows the evolution of the total water influx for the eruption with the phreatomagmatic phase (curve $J$ ). Fig. 11b shows the discharge evolution for two eruptions (respectively, curve $Q_{1}$ and $Q_{2}$ ). After an initial, strongly transient stage lasting about $5 \mathrm{~min}$, the eruption enters a quasi-static regime in which the magma discharge rate and the fragmentation front decrease with the decreasing chamber pressure. During the quasi-static regime, the purely magmatic eruption fades constantly over about 55 min until the discharge reaches a value at which the model loses validity due to other effects. The phreatomagmatic phase begins at about $30 \mathrm{~min}$ after the plug disruption when the fragmentation front comes close to the aquifer position $\left(x_{\mathrm{a}}=1.5 \mathrm{~km}\right)$. In $5 \mathrm{~min}$, the influx grows from zero to the maximum intensity and remains close to that for the rest of the model run. The water influx accelerates the descent of the fragmentation front and brings more fragmented material to the gas-particle dispersion: the evacuation of this material causes the maximum in the discharge rate. For the calculated set of parameters, the water influx causes a doubling of the discharge rate. The initiation of the phreatomagmatic phase is controlled by the evolution of the chamber pressure: connected with the coefficient $\theta$ in our model. For a larger chamber or a lower discharge, the onset of the phreatomagmatic phase will occur later in the eruption.

\section{Discussion}

Although the conduit flow model presented in this paper has many limitations, it captures the main physics of explosive eruption behaviour. Furthermore, the parameters for the stabilized eruption (fragmentation front position, discharge rate and others) are consistent with the parameters calculated by more elaborate steady-state model (Papale, 2001; Melnik et al., this volume). The calculations confirm the validity of our assumption of isothermal regime for purely magmatic explosive eruption. The time that is required for the eruption to stabilize is of the order of several minutes that gives a proof for reliability of steady-state approach for the modelling of sustained explosive eruptions.

The model is extended to account for the interaction between magma flow in the conduit and phreatic water from an aquifer that happens during phreatomagmatic eruptions. Several results emerge from our calculations of transient phreatomagmatic eruptions triggered by plug disruption. First of all, there is a possibility of damped oscillation in the discharge rate with a period of several minutes. This feature is commonly observed during phreatomagmatic eruptions and may give an explanation for the layered nature of phreatomagmatic deposits. Secondly, a transition from purely magmatic to phreatomagmatic eruption may occur as an eruption develops. In this case, the phreatomagmatic phase is associated with an increase in the discharge rate, as happened at Vesuvius in 79 AD (Sheridan et al., 1981). We suppose that this happens due to the injection of water from a deep, porous, unconfined aquifer, when water influx immediately reaches a high intensity. The emptying of the magma chamber and the resulting decrease in chamber pressure controls the timing of the transition to the phreatomagmatic phase.

In conclusion, the developed model becomes an elaborate tool for studying the transient dynamics of explosive eruptions. Many limitations including details of magma-water interaction, magma fragmentation, mass transfer in ascending magma and others should be overcome in the future.

Notation table

Symbol Name (units)

$\rho \quad$ mixture density $\left(\mathrm{kg} \mathrm{m}^{-3}\right)$ 
$\rho_{\mathrm{m}} \quad$ melt density $\left(\mathrm{kg} \mathrm{m}^{-3)}\right.$

$\rho_{\mathrm{g}} \quad$ exsolved gas density $\left(\mathrm{kg} \mathrm{m}^{-3}\right)$

$\rho_{\mathrm{w}} \quad$ water density $\left(\mathrm{kg} \mathrm{m}^{-3)}\right.$

$v \quad$ mixture velocity $\left(\mathrm{m} \mathrm{s}^{-1)}\right.$

$\alpha \quad$ gas volume fraction

$E \quad$ total magma energy per unit volume $(\mathrm{Pa})$

$P \quad$ mixture pressure $(\mathrm{Pa})$

$P_{\text {ch }} \quad$ chamber pressure $(\mathrm{Pa})$

$P_{\text {st }} \quad$ saturation pressure $(\mathrm{Pa})$

$P_{\text {mst }}$ magmastatic pressure $(\mathrm{Pa})$

$P_{\text {atm }} \quad$ atmospheric pressure $(\mathrm{Pa})$

$P_{\mathrm{w}} \quad$ water pressure $(\mathrm{Pa})$

$\alpha_{\mathrm{w}} \quad$ water compressibility coefficient $\left(\mathrm{Pa}^{-1}\right)$

$u \quad$ water velocity $\left(\mathrm{m} \mathrm{s}^{-1}\right)$

$T$ mixture temperature $(\mathrm{K})$

$T_{\text {ch }} \quad$ magma chamber temperature (K)

$T_{\mathrm{e}} \quad$ temperature of equilibrium water boiling (K)

$T_{\text {atm }}$ atmospheric temperature $(\mathrm{K})$

$T_{\mathrm{w}} \quad$ water temperature $(\mathrm{K})$

$k \quad$ aquifer permeability $\left(\mathrm{m}^{2}\right)$

$m$ aquifer porosity

$L \quad$ conduit length (m)

$D \quad$ conduit diameter $(\mathrm{m})$

$x_{\mathrm{f}} \quad$ fragmentation front position (m)

$x_{\mathrm{p}} \quad$ plug position (m)

$x_{\mathrm{a}} \quad$ aquifer position $(\mathrm{m})$

$h_{\mathrm{a}}$ aquifer thickness (m)

$\mu \quad$ magma viscosity ( $\mathrm{Pa} \mathrm{s}$ )

$\mu_{\mathrm{w}} \quad$ water viscosity (Pa s)

$k_{\mathrm{p}} \quad$ solubility coefficient $\left(\mathrm{Pa}^{-0.5}\right)$

$Q \quad$ discharge rate $\left(\mathrm{kg} \mathrm{s}^{-1}\right)$

$Q_{0} \quad$ steady discharge rate $\left(\mathrm{kg} \mathrm{s}^{-1)}\right.$

$j \quad$ water influx $\left(\mathrm{kg} \mathrm{s}^{-1} \mathrm{~m}^{-3}\right)$

$J \quad$ total water influx from the aquifer $\left(\mathrm{kg} \mathrm{s}^{-1}\right)$

$q \quad$ heat influx $\left(\mathrm{Pa} \mathrm{s}^{-1}\right)$

$\lambda_{\mathrm{w}} \quad$ latent heat of vaporization $\left(\mathrm{J} \mathrm{kg}^{-1}\right)$

$c_{\mathrm{V}} \quad$ vapour heat capacity $\left(\mathrm{J} \mathrm{kg}^{-1} \mathrm{~K}^{-1}\right)$

$w \quad$ water heat capacity $\left(\mathrm{J} \mathrm{kg}^{-1} \mathrm{~K}^{-1}\right)$

$\theta$ the coefficient for chamber pressure decreasing $\left(\mathrm{m} \mathrm{s}^{-2}\right)$

\section{Acknowledgements}

This work was supported by the INTAS and Russian Fundamental Research fund. The authors thank Alexander Proussevitch and Kenneth Wohletz for considerate reviews that improved this manuscript and Steve Sparks and Ed Llewellin for their advice and thorough criticism during preparation of this manuscript.

\section{Appendix A. On integrals of governing equations}

The integrals of the continuity equations appear as a consequence of the assumption of 1D one-velocity flow. Any of the continuity equations without a source term (1), (9), (17) can be represented in a following form:

$\frac{\mathrm{d} \ln \rho_{\#}}{\mathrm{~d} t}+\frac{\partial v}{\partial x}=0$

$\frac{\mathrm{d}}{\mathrm{d} t}=\frac{\partial}{\partial t}+v \frac{\partial}{\partial x}$

$\rho_{\#}=\rho,(1-\alpha)(1-c) \rho_{\mathrm{m}}, n$

Combining two of the equations in (30), we can obtain:

$\frac{\mathrm{d}\left(\rho /\left[(1-\alpha)(1-c) \rho_{\mathrm{m}}\right]\right)}{\mathrm{d} t}=0$

$\frac{\mathrm{d}\left((1-\alpha)(1-c) \rho_{\mathrm{m}} / n\right)}{\mathrm{d} t}=0$

The integrals of ratios (31) and (32) have constants taken from the nucleation front where $n=n_{0}, \alpha=0$, $c=c_{0}, \rho=\rho_{\mathrm{m}}$. Therefore, the ratio of densities is conserved at an individual particle if there is no external water influx into the conduit. With fixed constants, the integrals become Eqs. (10) and (18). Even if the nucleation occurs in the magma chamber, we still can use Eqs. (31) and (32) with constants from the nucleation front. Eq. (10) together with the mixture density definition (6) allows the equation of state for pressure (7) to be determined.

\section{Appendix B. Numerical method}

The code used to solve the transient problems (1)(8) and (2), (4)-(9), (21)-(25) is based on the LaxFriedrichs numerical method. The Lax-Friedrichs conservative method (Nessyahu and Tadmor, 1990; 
Guang-Shan and Tadmor, 1998) is applied for flow in the conduit. We use it since the system of governing equations (2),(4)-(9),(21)-(25) has a conservative form and can be represented as:

$$
\begin{aligned}
& \frac{\partial u}{\partial t}+A(u) \frac{\partial u}{\partial x}=\psi(u, t) \quad A(x)=\frac{\partial f(u)}{\partial u}(x) \\
& u=(\rho, Q, \chi, E), Q=\rho v, \chi=(1-c)(1-\alpha) \\
& f(u)=\left(Q, P+\rho v^{2}, \chi \rho_{\mathrm{m}} v(P+E) v\right) \\
& \psi=\left(j,-\rho g-f_{\mu}, 0,-Q g-f_{\mu} v-q\right)
\end{aligned}
$$

The method works on the equally spaced $x$-grid with step $\Delta x$. The $x$-grid has to be shifted on $0.5 \Delta x$ after each time step $\Delta t_{k}: x_{i}^{n}=x_{i}^{n+1}+0.5 \Delta x$. According to Nessyahu and Tadmor (1990), we chose $\Delta t_{k}$ to satisfy CFL conditions. At any time step, the vector function $u(x)$ is fitted by a piecewise-linear approximation. In order to account for discontinuities, we use the minmod function $\mathrm{MM}$, which chooses the best appropriate slope $u_{i}^{\prime}\left(x_{i}^{n}, t_{k}\right)$ from numerical derivatives for the approximation:

$$
M M\left(d_{1}, d_{2}, . . d_{n}\right)= \begin{cases}0 & \exists k, l: d_{k} d_{l} \leq 0 \\ \min _{i}\left(d_{i}\right) & \forall k d_{k}<0 \\ \max _{i}\left(d_{i}\right) & \forall k d_{k}>0\end{cases}
$$

Here, instead of parameters $d_{i}$ left, right or central derivatives are substituted. The principal method formulas follow from the approximation of Eq. (33) in the integral form on the rectangle $\left\{\left(x_{i}^{n}, t_{k}\right)\right.$, $\left.\left(x_{i}^{n}+\Delta x, t_{k}\right), \quad\left(x_{i}^{n+1}+0.5 \Delta x, t_{k+1}\right),\left(x_{i}^{n+1}-0.5 \Delta x, t_{k+1}\right)\right\}$. The method has two semi-steps: predictor which approximates the values $u\left(x_{i}^{n}, t_{k}+0.5 \Delta t_{k}\right)$, and corrector which calculates the values on the staggered grid $u\left(x_{i}^{n}+0.5 \Delta x, t_{k+1}\right)$.

$$
\begin{aligned}
u\left(x_{i}, t_{k}+0.5 \Delta t_{k}\right) \approx & u\left(x_{i}, t_{k}\right)+\frac{\Delta t_{k}}{\Delta x} f^{\prime}\left(u\left(x_{i}, t_{k}\right)\right) \\
u\left(x_{i}+0.5 \Delta x, t_{k+1}\right) \approx & \frac{1}{2}\left(u\left(x_{i}, t_{k}\right)+u\left(x_{i+1}, t_{k}\right)\right) \\
& +\frac{1}{8}\left(u^{\prime}\left(x_{i}, t_{k}\right)-u^{\prime}\left(x_{i+1}, t_{k}\right)\right) \\
& +\frac{\Delta t_{k}}{\Delta x}\left(f\left(u\left(x_{i+1}, t_{k}+0.5 \Delta t_{k}\right)\right)\right. \\
& \left.-f\left(u\left(x_{i}, t_{k}+0.5 \Delta t_{k}\right)\right)\right)
\end{aligned}
$$

To estimate the accuracy of this method, the transient task was solved until stabilization and stabilized profiles were compared with profiles from the steady-state solution that was solved by the integration of ODE. For 500 cells in the $x$-grid the steady and stabilize pressure profiles coincide to within $0.1 \%$.

The problem in the aquifer (24) is solved by an implicit method that leads to three-diagonal matrices that was solved my means of the Thomas method. For a fixed pressure at the edge and a finite aquifer radius an analytical steady-state solution for pressure profiles was compared with the stabilized result of the calculations. For 100 cells in the $r$-grid the analytical and stabilize pressures coincide to within $1 \%$.

In order to get an appropriate solution of the full problem (9),(2),(4),(6),(8),(21),(24),(25) we combine the two methods and iterate the influx to satisfy the boundary condition at the edge of the aquifer.

\section{References}

Allen, S.R., Cas, R.A.F., 1998. Rhyolitic fallout and pyroclastic density current deposits from a phreatoplinian eruption in the eastern Aegean Sea, Greece. Journal of Volcanology and Geothermal Research 86 (1-4), 219-251.

Arrighi, S., Principe, C., Rosi, M., 2001. Violent strombolian and subplinian eruption at Vesuvius during post-1631 activity. Bulletin of Volcanology 63, 126-150.

Barmin, A.A., Melnik, O.E., 1993. Features of eruption dynamics of high viscosity gas-saturated magmas. Izvestia Rossiskoi Akademii Nauk, Mekhanika Zhidkosti i Gaza 2, 49-57.

Barmin, A.A., Melnik, O.E., Starostin, A.B., 2003. Modelling of water influx influence on the flow in the volcano conduit. Izvestia Rossiskoi Akademii Nauk, Mekhanika Zhidkosti i Gaza $5,95-105$.

Cole, P.D., Queiroz, G., Wallenstein, N., Gaspar, J.L., Duncan, A.M., Guest, J.E., 1995. An historic subplinian/phreatomagmatic eruption: the $1630 \mathrm{AD}$ eruption of Furnas volcano, So Miguel, Azores. Journal of Volcanology and Geothermal Research 69, 117-135.

Delaney, P.T., 1982. Rapid intrusion of magma into wet rock: groundwater flow due to pore pressure increases. Journal of Geophysical Research 87, 7739-7756.

Doubik, Y.P., Hill, B.E., 1999. Magmatic and hydromagmatic conduit development during the 1975 Tolbachik eruption, Kamchatka, with implications for hazards assessment at Yucca Mountain, Nevada. Journal of Volcanology and Geothermal Research 91, 43-64.

Druitt, T.H., Young, S., Baptie, B., Calder, E., Clarke, A., Cole, P., Harford, C., Herd, R., Luckett, R., Ryan, G., Sparks, S., Voight, B., 2002. Episodes of cyclic Vulcanian explosive activity with 
fountain collapse at Soufri re Hills volcano, Montserrat. In: Druitt, T.H., Kokelaar, B.P. (Eds.) The Eruption of Soufrière Hills Volcano, Montserrat, from 1995 to 1999. Geological Society, London, Memoir.

Guang-Shan, J., Tadmor, E., 1998. Non-oscillatory central schemes for multidimensional hyperbolic conservation laws. SIAM Journal Scientific Computing 19, $1892-1917$.

Hess, K.U., Dingwell, D.B., 1996. Viscosities of hydrous leucogranitic melts: a non-Arrhenian model. American Mineralogist 81, 1297-1300.

Llewellin, E.W., Manga, M., 2005. Bubble suspension rheology and implications for conduit flow. J. Volcanol. Geotherm. Res. 143, 205-217 (this issue).

Llewellin, E.W., Mader, H.M., Wilson, S.D.R., 2002a. The rheology of a bubbly liquid. Proceedings of the Royal Society, A 458, 987-1016.

Llewellin, E.W., Mader, H.M., Wilson, S.D.R., 2002b. The constitutive equation and flow dynamics of bubbly magmas. Geophysical Research Letters 29 (article no. 2170).

Manga, M., Loewenberg, M., 2001. Viscosity of magmas containing highly deformable bubbles. Journal of Volcanology and Geothermal Research 105, 19-24.

Melnik, O., 2000. Dynamics of two-phase conduit flow of highviscosity gas-saturated magma: large variations of sustained explosive eruption intensity. Bulletin of Volcanology 62 (3), $153-170$.

Nessyahu, H., Tadmor, E., 1990. Non-oscillatory central differencing for hyperbolic conservation laws. Journal of Computational Physics 87, 408-463.

Pal, R., 2003. Rheological behaviour of bubble-bearing magmas. Earth and Planetary Science Letters 207, 165-179.

Papale, P., 2001. Dynamics of magma flow in volcanic conduits with variable fragmentation efficiency and nonequilibrium pumice degassing. Journal of Geophysical Research: Solid Earth 106, 11043-11065.

Pfeiffer, T., 2001. Vent development during the Minoan eruption (1640 BC) of Santorini, Greece, as suggested by ballistic blocks. Journal of Volcanology and Geothermal Research 106, 229-242.

Robertson, R.E.A., Cole, P., Sparks, R.S.J., Harford, C.L., Lejeune, A.-M., McGuire, W.J., Miller, A.D., Murphy, M.D., Norton, G., Stevens, N.F., the MVO Team, 1998. The explosive eruption of Soufrière Hills Volcano, Montserrat September 17, 1996. Geophysical Research Letters 25, 3429-3432.

Sahagian, D., 2005. Volcanic eruption mechanisms: insights form intercomparison of models of conduit processes. J. Volcanol. Geotherm. Res. 143, 1-15 (this issue).
Sheridan, M.F., Barberi, F., Rosi, M., Santacroce, R., 1981. A model for Plinian eruptions of Vesuvius. Nature 289, 282-285.

Slezin, Y.B., 1984. Dispersion regime dynamics in volcanic eruptions: 2. Flow rate instability condition and nature of catastrophic explosive eruptions. Vulkanologiya i Seismologiya $1,23-35$.

Slezin, Y.B., 2003. The mechanism of volcanic eruptions (a steady state approach). Journal of Volcanology and Geothermal Research 122 (1-2), 7-50.

Sparks, R.S.J., 1978. The dynamics of bubble formation and growth in magmas - a review and analysis. Journal of Volcanology and Geothermal Research 3, 1-37.

Troise, C., Castagnolo, D., Peluso, G., Mastrolorenzo, G., Gaeto, F.S., De Natale, F., 2001. A 2D mechanical-thermal fluiddynamical model for geothermal systems at calderas: an application to Campi Flegrei. Journal of Volcanology and Geothermal Research 109, 1-12.

Voight, B., Sparks, R.S.J., Miller, A.D., Stewart, R.C., Hoblitt, R.P., Clarke, A., Ewart, J., Aspinall, W., Baptie, B., Druitt, T.H., Herd, R., Jackson, P., Lockhart, A.B., Loughlin, S.C., Lynch, L., McMahon, J., Norton, G.E., Robertson, R., Watson, I.M., Young, S.R., 1999. Magma flow instability and cyclic activity at Soufriere Hills Volcano, Montserrat. B.W.I. Science 283, $1138-1142$.

White, J.D.L., 1996. Impure coolants and interaction dynamics of phreatomagmatic eruptions. Journal of Volcanology and Geothermal Research 74, 155-170.

White, J.D.L., Schmincke, H.U., 1999. Phreatomagmatic eruptive and depositional processes during the 1949 eruption on La Palma (Canary Islands). Journal of Volcanology and Geothermal Research 94, 283-304.

Wilson, L., Sparks, R.S.J., Walker, G.P.L., 1980. Explosive volcanic eruptions: IV. The control of magma properties and conduit geometry on eruption column behaviour. Geophysical Journal of Royal Astronomy Society 63, 117-148.

Wohletz, K., 2002. Magma/water interaction: some theory and experiments on peperite formation. Journal of Volcanology and Geothermal Research 114, 14-25.

Woods, A.W., 1995. A model of vulcanian explosions. Nuclear Engineering and Design 155, 345-357.

Woods, A.W., Koyaguchi, T., 1994. Transitions between explosive and effusive eruption of silicic magmas. Nature 370, 641-645.

Zimanowski, B., Büttner, R., 2002. Dynamic mingling of magma and liquefied sediments. Journal of Volcanology and Geothermal Research 114, 37-44. 